\title{
NORMAS PROCESSUAIS E NORMAS SUBSTANTIVAS: A PRIMAZIA DAS NORMAS DE JUS COGENS E O ENTENDIMENTO DA CORTE INTERNACIONAL DE JUSTIÇA
}

\begin{abstract}
PROCEDURAL NORMS AND SUBSTANTIVE NORMS: THE PRIMACY OF JUS COGENS NORMS AND UNDERSTANDING OF THE INTERNATIONAL COURT OF JUSTICE
\end{abstract}

\author{
${ }^{1}$ Elisa Resende Bueno da Fonseca
}

\section{RESUMO}

A proposta desse artigo é analisar a relação entre a norma processual de imunidade de Estado e a norma substantiva de jus cogens que proíbe a tortura e o trabalho escravo no caso Alemanha v. Itália julgado pela Corte Internacional de Justiça no ano de 2012. Em que pese a reconhecida superioridade das normas imperativas, no caso em espeque, sua análise foi impedida pela aplicação da norma processual de imunidade. A supressão da norma que expressa os valores superiores da comunidade internacional implicou em impunidade e injustiça manifesta. Por meio da análise pormenorizada das características e efeitos das normas substantivas de jus cogens, bem como, a sua distinção das normas de caráter processual, e considerando como marco a humanização do direito internacional e a busca pela efetividade dos direitos humanos, esse trabalho constatou que, de acordo com o Direito Internacional contemporâneo, não é possível que uma norma processual impeça a aplicação de uma norma substantiva de jus cogens, exatamente pelo valor supremo que essa última protege: a pessoa humana.

Palavras-chave: Norma processual, Norma substantiva, Jus cogens, Hierarquia, Justiça material

\begin{abstract}
The purpose of this paper is to analyze the relationship between the procedural rule of State immunity and substantive rule of jus cogens prohibiting torture and slave labor in the case Germany v. Italy judged by the International Court of Justice in 2012. Notwithstanding the recognized superiority of peremptory norms, in the case, its analysis was impeded by application of the procedural rule of immunity. The suppression of the rule that expresses the higher values of the international community resulted in manifest injustice and impunity. Through detailed analysis of the characteristics and effects substantive rules of jus cogens, as well as its distinction of rules of procedural character, and considering the theoretical framework humanization of international law, this work states that the contemporary international law does not allow a procedural rule prevents the application of a substantive rule of jus cogens, exactly by the supreme value this last protects: the human being.
\end{abstract}

Keywords: Procedural rules, Substantive rules, Jus cogens, Hierarchy, Material justice

\footnotetext{
${ }^{1}$ Mestrado em Direito pela Fundação Universidade de Itaúna, Minas Gerais (Brasil).

E-mail: elisaresendebueno@yahoo.com.br
} 


\section{INTRODUÇÃO}

Em 3 de fevereiro de 2012, a Corte Internacional de Justiça (CIJ) proferiu sua decisão no caso opondo a Alemanha à Itália ${ }^{1}$, Grécia interveniente, sobre imunidade de jurisdição e execução do Estado Alemão e os crimes nazistas.

Tal decisão foi ansiosamente esperada pela comunidade internacional ${ }^{2}$ porque trazia à tona a antiga discussão sobre o alcance da imunidade de Estado perante os tribunais estrangeiros, que, no referido caso, se opôs às reivindicações de indenização decorrentes de violações graves do direito internacional humanitário.

Isso porque, ao apresentar sua demanda à CIJ, a Alemanha alegou violação pela Itália da norma de direito internacional sobre imunidade de jurisdição e execução de Estado. Sob o argumento de que a Itália permitiu que seus Tribunais nacionais examinassem demandas judiciais interpostas contra a Alemanha e tomassem medidas coercitivas contra a propriedade Alemã Villa Vigoni, na Itália.

No entanto, além de apresentar contra memória à demanda interposta pela Alemanha, a Itália apresentou uma demanda reconvencional, alegando ter a Alemanha violado norma de jus cogens (como a proibição da tortura, do trabalho escravo e forçado) e a consequente obrigação de indenizar às vítimas italianas da $2^{\mathrm{a}}$ Guerra Mundial ${ }^{3}$.

Nesse mesmo sentido, a Grécia interviu nos autos pleiteando os direitos dos seus nacionais igualmente vitimados ${ }^{4}$.

Itália e Grécia argumentaram que uma norma imperativa de direito internacional geral, ou seja, uma norma de jus cogens, se sobrepõe a qualquer norma hierarquicamente inferior advinda do direito consuetudinário ou convencional que impedir a aplicabilidade daquela. Exposto de outra forma, os dois Estados aduziram que a regra de jus cogens é superior e tem primazia na aplicabilidade frente à norma de imunidade de Estado.

${ }^{1}$ CIJ. Jurisdictional Immunities of the State (Germany v. Italy; Greece intervening). Judgment, ICJ Reports, 3 February 2012 . Disponível em: <http://www.icjcij.org/docket/index.php?p1=3\&p2=3\&k=60\&case=143\&code=ai\&p3=4>. Acessado em: 26 de novembro de 2013.

2 Cf. BORNKAMM, Paul Christoph. State Immunity Against Claims Arising from War Crimes: The Judgment of the International Court of Justice in Jurisdictional Immunities of the State. Disponível em: <http://www.germanlawjournal.com/pdfs/Vol13-No6/PDF_Vol_13_No_06_773-

782_Bornkamm\%20FINAL.pdf>. Acesso em: 26 de novembro de 2013.

3 CIJ. Counter-Memorial of Itália 22 de dezembro de 2009. Disponível em: <http://www.icjcij.org/docket/files/143/16648.pdf>. Acessado em 26 de novembro de 2013.

${ }^{4}$ CIJ. Application for permission to intervene by the government of the Hellenic Republic. 13 de janeiro de 2011. Disponível em: < http://www.icj-cij.org/docket/files/143/16304.pdf>. Acessado em: 22 de novembro de 2013. 
A partir de então, surgiu uma controvérsia, não originalmente prevista, cuja solução exigiu uma posição da CIJ. A sentença foi adotada por doze juízes da Corte, que afirmaram a existência de imunidade do Estado Alemão, sendo que três, dentre eles o brasileiro Antônio Augusto Cançado Trindade, emitiram votos dissidentes ${ }^{5}$.

A decisão da Corte cuidou de enfrentar os principais pontos polêmicos levantados pelas partes litigantes e pelo terceiro interveniente. No entanto, ao dispor sobre a natureza das normas de direito internacional em análise e suas respectivas posições no plano hierárquico, a CIJ não justificou seu posicionamento, se limitando a aduzir que a norma processual de imunidade de Estado impedia a análise do direito substantivo de jus cogens ${ }^{6}$.

A decisão da Corte baseou-se na lógica de que o argumento da Itália e da Grécia dependia da existência de um conflito de normas entre jus cogens e a regra do direito consuetudinário de imunidade de Estado. E, na opinião da maioria do Tribunal, esse conflito não existia, exatamente porque as duas normas têm naturezas diferentes: enquanto a norma de jus cogens tem natureza substantiva, dispõe sobre direito material, a norma de imunidade de Estado tem caráter processual ${ }^{7}$.

Contudo, essa não foi a primeira vez que a CIJ se referiu à distinção entre o direito substantivo e o direito processual. No Caso Mandado de Prisão de $1^{\circ}$ de abril de 2000 (República Democrática do Congo v. Bélgica), julgado em 2002, a CIJ considerou que imunidade de jurisdição criminal e responsabilidade individual criminal são conceitos distintos, já que a norma de imunidade jurisdicional tem natureza processual, porquanto a norma de responsabilidade criminal tem natureza de direito substantivo ${ }^{8}$. Tal argumento levou a Corte a concluir que "a imunidade de jurisdição pode muito bem barrar a ação penal durante certo período ou em relação a determinados crimes" $"$.

Desde então, a distinção entre normas substantivas de jus cogens e normas processuais vem sendo muito criticada por estudiosos do direito internacional ${ }^{10}$. Muitos

\footnotetext{
A decisão da maioria e os votos separados estão disponíveis no endereço eletrônico da CIJ: <http://www.icjcij.org/docket/index.php?p1=3\&p2=3\&k=60\&case=143\&code=ai\&p3=4>.

${ }^{6}$ CIJ, 2012, parágrafos 50 e 100. CIJ. Summary of the Judgment of 3 February 2012. p. 4. Disponível em: <

http://www.icj-cij.org/docket/files/143/16899.pdf>. Acessado em: 20 de dezembro de 2013.

${ }^{7}$ CIJ, 2012, parágrafo 93.

${ }^{8}$ CIJ. Reports of Judgments Case Concerning The Arrent Warrant of 11 April 2000 (Democratic Republic

Of The Congo V. Belgium). Judgment of 14 february 2002. Parágrafo 60. Disponível em: < http://www.icjcij.org/docket/files/121/8126.pdf>. Acessado em 16 de junho de 2014.

${ }^{9}$ Ibid., parágrafo 60 .

${ }^{10}$ É claro que também existem aqueles que acompanham o raciocínio jurídico da Corte e concordam com a distinção substantivaprocessual em caso de jus cogens, como exemplo: TALMON, Stefan. Jus Cogens after Germany v. Italy: Substantive and Procedural Rules Distinguished. In: Bonn Research Papers on Public

International Law. Paper n. 4/2012, 16 de junho de 2012, p.4. Vale destacar o entendimento do autor:

"Substantive and procedural rules are not ejusdem generis, that is, they are not of the same kind. The two sets of
} 
criticam por seu "formalismo excessivo"11. O juiz Van den Wyngaert, em sua opinião dissidente, disse que se trata de uma "proposição puramente doutrinal, que não se baseia no direito internacional consuetudinário ou convencional ou na prática nacional, e que não é suportado por parte substancial da doutrina jurídica"12. O professor Riccardo Pavoni, por sua vez, afirma que essa distinção "parece demasiadamente formalista e distante da realidade de proteção dos direitos humanos"

Segundo Stefan Talmon, “muitos dos argumentos e críticas parecem ser motivados pelo resultado indesejado da distinção „substantiva-processual“, ou seja, a verdadeira impunidade pelas violações mais graves dos direitos humanos" $" 14$.

Sem dúvida, a discussão da distinção por si só não desperta tanto interesse, todavia, quando somado as suas consequências, particularmente no Caso Alemanha v. Itália - no qual vítimas de crimes gravíssimos contra a humanidade ficaram sem qualquer reparação, com a consequente impunidade do Estado violador -, o tema provoca indignação e curiosidade.

Sob esse enfoque, o presente trabalho cuidará de analisar inicialmente as principais discussões sobre a distinção substantiva-processual levantadas no caso Alemanha v. Itália, em seguida, fará um estudo sobre as normas de jus cogens e seus pormenores, para, ao final, avaliar a decisão da CIJ e seus efeitos no âmbito do direito internacional contemporâneo. Para tanto, adotar-se-á como marco a teoria da Humanização do Direito Internacional ou o Direito Internacional para a Humanidade defendida por Antônio Augusto Cançado Trindade.

\footnotetext{
rules address different matters. They have different contents and therefore do not impose incompatible obligations. While the former address the question of the lawfulness of a situation or conduct, the latter deal with rule interpretation, implementation and enforcement. There may be indirect and occasional collisions between the two, but there is no logical conflict between substantive rules and rules of a procedural character. This is true for both the relationship between ordinary substantive and procedural rules and for the relationship between substantive rules of a jus cogens character and procedural rules. A jus cogens rule is one from which no derogation is permitted, but the application of a procedural rule does not amount to derogation from substantive rules of jus cogens. A procedural rule may hinder the application or enforcement of the jus cogens rule; but it does not derogate from its content."

${ }^{11}$ Como por exemplo, MC GREGOR, Lorna. Torture and State Immunity: Deflecting Impunity, Distorting Sovereignty. In: EJIL 18, páginas 903-911, 2007, p. 911.

${ }_{12}$ CIJ, 2002, p. 159, parágrafo 33. Opinião dissidente de Van den Wyngaert: “(...) the International Court of Justice has adopted a purely doctrinal proposition. which is not based on customary or conventional international law or on national practice and which is not supported by a substantial part of legal doctrine. It is particularly unfortunate that the International Court of Justice adopts this position without giving reasons".

${ }^{13}$ PAVONI, Riccardo. Human Rights and the Immunities of Foreign States and International Organizations. In: DE WET, Erika; VIDMAR, Jure (edited). Hierarchy in International Law: The Place of Human Rights. Oxford, 2012. ${ }^{14}$ TALMON, 2012, p.3.
} 


\section{AS DIVERSAS ABORDAGENS SOBRE NORMAS PROCESSUAIS E NORMAS SUbSTANTIVAS DE JUS COGENS APONTADAS NO CASO ALEMANHA V. ITÁLIA}

No caso em espeque, a controvérsia sobre a relação entre normas substantivas de jus cogens e normas processuais de imunidade de Estado tem início quando da primeira manifestação da Itália nos autos ${ }^{15}$.

Em sua peça inicial, a Alemanha aduz apenas a violação pela Itália da norma do Direito Internacional Consuetudinário que prevê que um Estado deve conceder imunidade de jurisdição e execução a outro Estado quando se tratar de ato jure imperii, ou seja, quando o ato tiver sido praticado pelo Estado no uso de sua soberania.

De acordo com a Alemanha, os crimes de guerra cometidos pelas autoridades do Terceiro Reich, foram atos de Estado, e, portanto, devem ter o privilégio da imunidade de jurisdição e execução de Estados ${ }^{16}$.

A Itália, então, vem aos autos argumentando, dentre outros pontos, que a norma violada pela Alemanha Nazista é norma de jus cogens, e, portanto, hierarquicamente superior à norma processual de imunidade de Estado.

De acordo com a Itália, os crimes contra a humanidade perpetrados pelo Estado Alemão durante o Terceiro Reich não podem ser considerados atos de império, e, por conseguinte, não podem ficar acobertados pelo manto da imunidade.

Em suas alegações orais, a Alemanha traz à tona a distinção entre normas primárias e normas secundárias do direito internacional ${ }^{17}$. E começa a explanação afirmando que as normas de jus cogens são primárias, porquanto a norma processual de imunidade é secundária. Segundo ela, o status peremptório de uma regra diz respeito a sua natureza intrínseca como uma proposição irrevogável, isto é, seu status de norma primária. No entanto, não existem disposições legais gerais que regem as consequências da violação dessas normas. E tais regulamentos não podem ser inventados na análise de um caso individual. Desse modo,

${ }^{15}$ CIJ, 2009.

${ }^{16}$ CIJ. Application Instituting Proceedings Jurisdictional Immunities of the State (Germany v. Italy) de 23 december 2008. Disponível em: <http://www.icj-cij.org/docket/files/143/14923.pdf>. Acessado em: 20 de janeiro de 2014.

${ }^{17}$ CIJ. Public sitting held on Monday 12 September 2011, at 10 a.m., at the Peace Palace, President Owada presiding, in the case concerning Jurisdictional Immunities of the State (Germany $v$. Italy: Greece intervening). CR 2011/17. p. 49-50, parágrafo 3. Disponível em: <http://www.icjcij.org/docket/index.php?p1=3\&p2=3\&k=60\&case=143\&code=ai\&p3=2>. Acessado em: 20 de janeiro de 2014 . 
o jus cogens não pode prevalecer sobre as regras secundárias exatamente porque esse conceito não indica uma hierarquia normativa generalizada ${ }^{18}$.

Mais adiante, ainda nas alegações orais, a Alemanha afirma que a norma de jus cogens não pode ser utilizada como uma norma hierarquicamente superior em casos de conflito entre duas normas do Direito Internacional Geral (sendo uma peremptória e a outra não peremptória) ${ }^{19}$ justamente porque não pode haver conflito entre duas regras de Direito Internacional Geral. Do contrário, o ordenamento jurídico internacional seria autocontraditório. Ademais, uma norma consuetudinária deve sempre ser apoiada pela prática geral e opinio juris. Nesse sentido, o que pode existir é a modificação de uma norma (total ou parcialmente) pela aplicação de outra devidamente apoiada pela comunidade internacional. Nessa linha, segundo a Alemanha, a prática atual dos Estados não indica que as regras de imunidade do Estado têm sido modificadas de alguma forma ${ }^{20}$.

$\mathrm{Na}$ mesma audiência, a Itália, logo em seguida, afirma que o argumento da Alemanha "reflete claramente uma visão muito estreita do conceito de jus cogens" "21. Já que os efeitos de jus cogens não estão confinados dentro da esfera de regras primárias. De acordo com a Itália, existem casos limítrofes em que o Direito Internacional permite a remoção de imunidade, a fim de permitir o cumprimento eficaz das regras de jus cogens ${ }^{22}$. Exposto de outra forma, a Itália defende a tese de que, no caso em espeque, existe um conflito irreconciliável entre a regra processual de imunidade e a regra substantiva de jus cogens, no qual deve ser dada prioridade à efetivação da norma peremptória.

A Grécia, terceiro interveniente não parte, aduziu que, de acordo com o entendimento de seus tribunais, particularmente na análise do Caso Massacre de Distomo, se as regras internacionais de caráter peremptório forem violadas a imunidade de Estado não pode ser invocada ${ }^{23}$. Na opinião do Estado interveniente, distinguir a norma processual (imunidade de Estado) da norma substantiva (jus cogens) não tem relevância jurídica ${ }^{24}$.

18 Ibid., parágrafo 3.

${ }^{19}$ Ibid., parágrafo 6 .

${ }^{20}$ Ibid., parágrafo 6.

${ }^{21}$ CIJ. Public sitting held on Tuesday 13 September 2011, at 10 a.m., at the Peace Palace, President Owada presiding, in the case concerning Jurisdictional Immunities of the State (Germany $v$. Italy: Greece intervening). CR 2011/18. p. 47-48, parágrafo 25. Disponível em: <http://www.icjcij.org/docket/index.php?p1=3\&p2=3\&k=60\&case=143\&code=ai\&p3=2>. Acessado em: 20 de janeiro de 2014 .

${ }_{22}^{2}$ Ibid., p. 49, parágrafo 28.

${ }^{23}$ CIJ. Public sitting held on Wednesday 14 September 2011, at 10 a.m., at the Peace Palace, President Owada presiding, in the case concerning Jurisdictional Immunities of the State (Germany v. Italy: Greece intervening). CR 2011/19. p. 36, parágrafo 98. Disponível em: < http://www.icj-

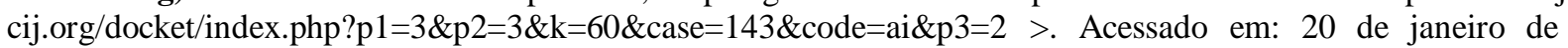
2014.

${ }^{24}$ Ibid., p.37, parágrafo 102 . 
Ademais, a norma processual não pode prevalecer sobre a norma substantiva de jus cogens, pois produziria uma situação jurídica insustentável, incompatível com a finalidade e a razão da regra primária substantiva de jus cogens, resultando em verdadeira impunidade dos Estados violadores das normas peremptórias ${ }^{25}$.

Ainda em suas alegações orais, a Grécia afirmou que a distinção substantivaprocessual prejudicaria também o direito ao acesso efetivo à justiça, já que as vítimas não serão capazes de pleitear a reparação perante os tribunais competentes, e o Estado violador jamais assumirá suas responsabilidades, particularmente no que diz respeito à reparação dos vitimados ${ }^{26}$. Logo, "uma regra de jus cogens, por sua natureza e conteúdo, prevalece sobre qualquer outra regra internacional" 27 .

Em seus memoriais, a Alemanha volta com a discussão para dizer que o fato do Estado Alemão gozar de imunidade não tornam legais os crimes contra a humanidade em flagrante violação às normas de jus cogens perpetrados pelo Terceiro Reich, mas, apenas que existe uma regra processual do Direito Internacional Consuetudinário que impede que a Itália julgue o Estado Alemão por tais atos ${ }^{28}$.

Ao final, após análise das diversas abordagens constantes nos autos, a CIJ, sem qualquer fundamentação, seguindo o precedente de 2002, caso do Mandado de Prisão República Democrática do Congo v. Bélgica, declarou que a norma processual de imunidade de Estado é inteiramente distinta do direito substantivo que determina se a conduta é lícita ou ilícita $^{29}$. Desse modo, a Corte entendeu que não existe conflito entre tais normas, no entanto, declarou que a incidência da norma processual de imunidade do Estado impede a análise do direito substantivo de jus cogens ${ }^{30}$.

Assim, no caso em estudo, a norma processual funcionou como uma barreira à análise do mérito da demanda, que se tratava de nada mais nada menos que crimes contra a humanidade da maior gravidade, verdadeiras violações às normas de jus cogens.

\footnotetext{
${ }^{25}$ Ibid. parágrafo 102. A título de exemplo, a Grécia cita a norma de jus cogens de proibição da tortura. Acaso a regra de imunidade de Estado impedisse à análise do crime de tortura, não haveria reparação às vitimas, nem punição do autor da violação.

${ }^{26}$ Ibid., p. 38, parágrafo 106.

${ }^{27}$ Ibid., p. 37, parágrafo 102.

${ }^{28}$ CIJ. Memorial of the Federal Republic of Germany Jurisdictional Immunities of the State (Germany v. Italy: Greece intervening). 12 de junho de 2009. Parágrafo 87. Disponível em: < http://www.icjcij.org/docket/files/143/16644.pdf>. Acessado em: 20 de janeiro de 2014.

${ }^{29}$ CIJ, 2012, parágrafo 50.

${ }^{30}$ CIJ, 2012, parágrafo 100.
} 
Nesse momento, as imagens do horror da Guerra ilustradas por diversos filmes ${ }^{31} \mathrm{e}$ $\operatorname{livros}^{32}$ vem à cabeça, e começam a passar, uma a uma, feito um pesadelo. Os campos de concentração, a separação das famílias, o medo, a fome, o trabalho forçado, as dores, a descartabilidade das cobaias, os massacres de vilas inteiras: idosos, crianças, deficientes, o abuso das mulheres, as torturas mais absurdas e depois de tudo, a morte. E, para quem fica, a dor que nunca passa, e que se soma e se multiplica com a dor da falta de cada uma das pessoas queridas que se foram, não porque Deus quis, mas por motivos que não se consegue explicar.

E, agora, depois que a Guerra termina, fica para o Direito resolver essas questões. Especificamente, o Direito Internacional.

\section{AS NORMAS DE JUS COGENS NO DIREITO INTERNACIONAL CONTEMPORÂNEO}

Considerando que o objetivo da presente pesquisa é analisar a relação entre normas processuais e normas substantivas de jus cogens, particularmente no caso Alemanha v. Itália, faz-se necessário debruçar sobre o tema jus cogens e todas as suas peculiaridades no direito internacional contemporâneo.

As normas de jus cogens, devido ao seu conteúdo "mais importante",33, são fundamentais porque dão as diretrizes e os contornos do próprio direito internacional.

Ao afirmar os valores que a sociedade internacional entende como primordial, as normas de jus cogens carregam as principais finalidades do direito. Servem, concomitantemente, como limites e guias para a aplicação do direito interno e internacional.

\footnotetext{
${ }^{31}$ Como: O JULGAMENTO de Nuremberg. Direção: Yves Simoneau. Interpretes: Alec Baldwin; Brian Cox; e outros. Estúdio: Warner Home Vídeo. Duração: 180 minutos. DVD. Canadá / EUA, 2000. A MENINA que roubava livros. Direção: Brian Percival. Interpretes: Geoffrey Rush; Emily Watson, Sophie Nélisse; e outros. DVD. EUA / Alemanha, 2014. A VIDA é bela. Direção: Roberto Benigni. Produção: Gianluigi Braschi; Elda Ferri. Interpretes: Roberto Benigni; Nicoletta Braschi; e outros. DVD. Itália, 1997.

${ }^{32}$ Como: CAPPELlETO, Francesca. Memory and World War II: na ethnographic approach. New York: BERG OXFORD, 2005; MAZOWER, Mark. O Império de Hitler: a Europa sob o domínio Nazista. Tradução Cláudio Carina; Lúcia Boldrini. 1.ed. São Paulo: Companhia das Letras, 2013; ZWEIG, Stefan. O Mundo que eu vi (minhas memórias). Tradução Odilon Gallotti. Rio de Janeiro: Guanabara, 1942.
} 
Embora a origem das normas de jus cogens seja anterior a $2^{\mathrm{a}}$ Guerra Mundial, vale destacar o que foi colocado pela Comissão do Direito Internacional das Nações Unidas em 1976:

\begin{abstract}
"O sentimento de horror deixado pelos massacres sistemáticos de milhões de seres humanos cometidos pelo regime nazista, e a indignação sentida em agressões completamente brutais sobre a vida e a dignidade humanas, têm ambos apontado para a necessidade de assegurar que não só a lei interna dos Estados, mas, acima de tudo, a lei da própria comunidade internacional deve estabelecer normas peremptórias que garantam que os direitos fundamentais dos povos e da pessoa humana serão salvaguardados e respeitados; tudo isso tem solicitado a afirmação mais vigorosa da proibição de crimes como o genocídio, o apartheid e outras práticas desumanas desse tipo". 34
\end{abstract}

Assim, a afirmação das normas de jus cogens no direito internacional contemporâneo acaba por estabelecer um mínimo de verticalização na ordem jurídica internacional, a qual, segundo Cançado Trindade, é erguida sobre pilares em que o direito e a ética são mesclados ${ }^{35}$.

O jus cogens foi definitivamente incorporado ao universo conceitual do Direito Internacional a partir de sua inclusão na Convenção de Viena sobre direito dos tratados, em 1969, como "normas imperativas de direito internacional geral"36.

De acordo com a Convenção de Viena, as normas de jus cogens são aceitas e reconhecidas por toda a comunidade internacional como normas que não permitem derrogação e que só podem sofrer modificações por norma ulterior de Direito Internacional geral da mesma natureza. Por esse motivo, é nulo o tratado que conflite com uma norma de jus $\operatorname{cogens}^{37}$. Da mesma forma que, se sobrevier uma norma ulterior imperativa de Direito

\footnotetext{
${ }^{34}$ ONU. Yearbook of the International Law Commission (1976). Vol. II. parte II. p. 109 e 113-114, e Cf. p. 119 .

${ }^{35}$ CANÇADO TRINDADE, Antônio Augusto. International Law for Hamankind: Towards a New Jus Gentium - General Course on Public International Law - Part I, in Hague Academy of International Law. Offprint from the Collected Courses. vol. 316, Martinus Nijhoff Publishers. 2005, p.336.

${ }^{36}$ Texto original: "Article 53. Treaties Conflicting with a Peremptory Norm of General International Law (jus cogens) a treaty is void if, at the time of its conclusion, it conflicts with a peremptory norm of general international law. For the purposes of the present Convention, a peremptory norm of general international law is a norm accepted and recognized by the international community of States as a whole as a norm from which no derogation is permitted and which can be modified only by a subsequent norm of general international law having the same character." Convenção de Viena sobre o Direito dos Tratados. 23.05.1969. Sobre toda a Convenção de Viena, cf. SALIBA, Aziz Tuffi. Direito dos Tratados: comentários à Convenção de Viena sobre o direito dos tratados (1969). Aziz Tuffi Saliba, autor e organizador; Ana Cristina Zadra Valadares e André de Carvalho Ramos. Belo Horizonte: Arraes Editores, 2011.

37 Ibid., art.53.
} 
Internacional geral, os tratados existentes que estiverem em conflito com a nova norma tornam-se nulos e extintos ${ }^{38}$.

No entanto, ao conceituar as normas imperativas, a Convenção não cuidou de arrolar as normas de jus cogens, mas se limitou a identifica-las como normas do direito internacional geral, as quais "existem fora e independentemente da Convenção"39.

Isso porque, o jus cogens é um construído, em constante evolução e expansão. Sendo, pois, "uma categoria aberta, que se expande na medida em que a consciência jurídica universal desperta para a necessidade de proteger os direito inerentes a cada ser humano em toda e qualquer situação" 40 .

Não se discute que, como o passar do tempo, as noções de certo e errado, e, por conseguinte de legal e ilegal, foram se modificando. Antes o trabalho escravo era uma prática permitida, com o tempo, o mundo inteiro foi aos poucos incorporando valores como igualdade e dignidade da pessoa humana, resultando na proibição internacional da mão de obra escrava. Hoje, no entanto, não se olvida de que a proibição da escravidão é uma norma imperativa do direito internacional. É abominada pela consciência jurídica universal. E assim acontece o tempo todo em todo o mundo com diversos valores, conceitos e princípios. A evolução do mundo implica também na evolução humana e, evidentemente, na evolução do direito.

É nesse sentido que Cançado Trindade constata uma gradual expansão do conteúdo material de jus cogens ${ }^{41}$. Segundo o autor, nos últimos anos, a consciência jurídica universal, expressa principalmente pelas jurisprudências internacionais contemporâneas, reconheceu como normas imperativas do direito internacional a absoluta proibição da tortura e do tratamento cruel, desumano ou degradante; o princípio da igualdade e não discriminação; e a fundamentabilidade do direito de acesso à justiça.

No entanto, não se tem uma posição única de quais são as normas do direito internacional que possuem caráter de jus cogens. Aziz Saliba faz larga pesquisa buscando o

\footnotetext{
${ }^{38}$ Ibid., art. 64. Texto original: "Article 64. Emergence of new Peremptory Norm of General International Law (jus cogens) If a new peremptory norm of general international law emerges, any existing treaty which is in conflict with that norm becomes void and terminates".

${ }^{39}$ NASSER, 2005, p.165.

${ }^{40}$ CANÇADO TRINDADE, 2005, p. 340. Texto original: "Moreover, the jus cogens, in my understanding, is an open category, which expands itself to the extent that the universal juridical conscience (material source of all Law) awakens for the necessity to protect the rights inherent to each human being in every and any situatio".

${ }^{41}$ CANÇADO TRINDADE, Antônio Augusto. Jus Cogens: The determination and the gradual expansion of its material contente in contemporary international case-law. Disponível em: < http://www.oas.org/dil/esp/3\%20-\%20cancado.LR.CV.3-30.pdf>. Acessado em: 04 de março de 2014.
} 
que se tem de consenso sobre o conteúdo material de tais normas ${ }^{42}$. O autor constata que é mais seguro aceitar como normas de jus cogens os exemplos aceitos pela maioria dos membros da Comissão de Direito Internacional: uso ilegal da força, genocídio, tráfico de escravos e pirataria, mas destaca que esses são apenas exemplos, o que significa que outras normas podem já ter alcançado o status de jus cogens, no entanto, acredita que não são amplamente reconhecidas como tais ${ }^{43}$.

As imprecisões existem, e isso é indiscutível. No entanto, sendo o conteúdo do jus cogens reflexo da consciência jurídica universal, um maior detalhamento pela Convenção não o tornaria mais preciso. É exatamente a evolução do direito internacional que vai guiar a expansão das normas imperativas. Nesse sentido, é preciso compreender o contexto internacional e, principalmente, os valores que toda a comunidade tem entendido como primordiais $^{44}$.

Nessa linha de entendimento, a diferença entre uma norma imperativa e outra norma de direito costumeiro de caráter geral se encontra na forma como a norma foi aceita e reconhecida: o jus cogens, em razão do seu conteúdo e valores por ele expressos, tem de ser aceito e reconhecido como norma da qual não se admite derrogação.

A característica mais importante das normas de jus cogens reside na sua substância, na sua materialidade. Essa característica é também seu diferencial, já que, todas as normas internacionais de origem convencional ou costumeira "surgem das fontes conhecidas de direito internacional e não há procedimento específico e diverso para a sua produção" ${ }^{45}$.

Quanto ao conceito, é importante destacar que o jus cogens não é limitado ao direito dos tratados, aplica-se também às normas que dispõem sobre a responsabilidade dos Estados. Nos dizeres de Cançado Trindade, jus cogens "é uma construção conceitual que ocupa uma posição central no novo jus gentium, o Direito Internacional para a humanidade”.

Assim, as normas de jus cogens refletem as conquistas jurídicas da humanidade, que, ao longo dos anos, têm sido reconhecidas por diversos países, com ambientes e culturas distintos. Daí dizer que, tais normas surgiram para conferir uma dimensão ética e universal do

42 SALIBA, Aziz Tuffi. Conselho de Segurança da ONU: sanções e limites jurídicos. Curitiba: Juruá, 2009, p.107-109.

43 Ibid., p. 109.

44 Para compreender o desenvolvimento do direito internacional, vale a leitura das obras do autor CANÇADO TRINDADE, Antônio Augusto. A Humanização do Direito Internacional. Belo Horizonte: Del Rey, 2006; A visão Humanista do Direito Internacional. Belo Horizonte: Del Rey, 2013; International Law for Hamankind: Towards a New Jus Gentium - General Course on Public International Law - Part I e II, in Hague Academy of International Law. Offprint from the Collected Courses. vol. 316, Martinus Nijhoff Publishers. 2005.

45 NASSER, 2005, p. 167. 

Direito Internacional contemporâneo e, portanto, devem ser aplicadas em prol de todos os seres humanos, e, em última análise, da humanidade. Do contrário, o próprio escopo do direito estaria sendo violado.

\subsection{As obrigações erga omnes como reflexo necessário das normas de jus cogens}

Da mesma forma que as normas de jus cogens estabelecem direitos coletivos universais para toda a comunidade internacional, independentemente do consentimento do Estado, também geram deveres coletivos universais de respeitar e garantir o respeito às normas de proteção, em todas as circunstâncias.

Para Cançado Trindade, um dos elementos subjacentes ao conceito de jus cogens está na ideia de que sua violação implica em verdadeira ilegalidade objetiva, que, por conseguinte, resulta em responsabilidade objetiva internacional do Estado violador.

$\mathrm{E}$ isso porque, nos dias atuais, ninguém se atreveria negar a ilegalidade objetiva de atos de genocídio, de práticas de tortura, de trabalho escravo, de desaparecimento forçado de pessoas - práticas que, nas palavras de Cançado Trindade, representam verdadeiros "crimes contra a humanidade" 46 . E que, assim o são, porque são condenados pela consciência jurídica universal, paralelamente à aplicação dos tratados.

Nesse sentido, diferentemente do direito internacional baseado no voluntarismo dos Estados, que cria obrigações inter partes, as obrigações erga omnes do direito internacional seriam aquelas que criam direitos para todos os Estados coletivamente ou para cada um deles individualmente. De forma que, violada uma dessas obrigações a comunidade dos Estados ou qualquer um deles isoladamente teria interesse jurídico legítimo na reparação e na proteção dos direitos imperativos em causa ${ }^{47}$. Nos dizeres de Aziz Tuffi Saliba, nas normas de jus cogens "o interesse coletivo da comunidade internacional prevalece sobre a vontade individual do Estado" $"$.

A Corte Internacional de Justiça, em seu acórdão no caso Barcelona Traction (Second Phase, 1970), determinou que algumas obrigações internacionais erga omnes são do interesse de todos os Estados na medida em que decorrem, por exemplo, no direito

${ }^{46}$ CANÇADO TRINDADE, 2005, p. 343.

${ }^{47}$ NASSER, 2005, p.171.

${ }^{48}$ SALIBA, 2009, p. 105. 
internacional contemporâneo, da proibição de atos de agressão e de genocídio, e também dos princípios e das regras relativas aos direitos fundamentais da pessoa humana, incluindo a proteção contra a escravidão e a discriminação racial ${ }^{49}$.

As vedações referidas nesta decisão não compõem um rol taxativo das obrigações erga omnes ${ }^{50}$. Até porque, nem todas as obrigações erga omnes são reflexos das normas de jus cogens ${ }^{51}$.

Por outro lado, todas as normas de jus cogens criam obrigações erga omnes ${ }^{52}$. De modo que, assim como o jus cogens, as novas proibições também foram adicionadas pela mais recente jurisprudência dos tribunais internacionais contemporâneos ${ }^{53}$, o que demonstra que, sendo o jus cogens uma categoria aberta, as obrigações erga omnes dele decorrentes também devem ser.

É possível afirmar, portanto, que a ordem jurídica internacional contemporânea encontra-se em processo de construção. Nesse processo se assiste o gradual desaparecimento da ideia do voluntarismo estatal e o surgimento, pari passu, das considerações superiores de ordem pública, as quais refletem nas normas de jus cogens e nas respectivas obrigações erga omnes.

De qualquer forma, no domínio do Direito Internacional dos Direitos Humanos, as obrigações erga omnes devem assim ser aplicadas: frente a todos, diante de todos, considerando que cada Estado tem um interesse jurídico na salvaguarda dos direitos humanos. Esta obrigação geral de proteção é, ao mesmo tempo, uma garantia coletiva da comunidade internacional e um interesse direto de cada Estado e de todos eles conjuntamente, em qualquer circunstância.

\subsection{As dimensões de eficácia das normas de jus cogens}

${ }^{49}$ Cf. CIJ. Barcelona Traction, Light and Power Company, Limited (Belgium v. Spain) Judgment of 5 February 1970. ICJ Reports 1970, p. 32, parágrafos 33 e 34. Disponível em: < http://www.icjcij.org/docket/index.php?p1=3\&p2=3\&k=4e\&case=41\&code=bt\&p3=6>. Acessado em: 02 de junho de 2014.

${ }^{50}$ PAULUS, Andreas L. Jus Cogens in a Time of Hegemony and Fragmentation: an attempt at a re-appraisal. In: Nordic Journal of International Law. 74. 2005, p. 313.

${ }^{51}$ CIDH. Opinión Consultiva OC-18/03. Solicitada por los Estados Unidos Mexicanos. Condición Jurídica y Derechos de los Migrantes Indocumentados. Disponível <http://www.cdh.uchile.cl/media/publicaciones/pdf/15/229.pdf>. Acessado em: 03 de abril de 2014. p. 80.

${ }^{52}$ Nesse sentido, destaca-se o entendimento de Aziz Tuffi Saliba: "Com esteio em Bassiouni, entendemos que jus cogens é o status jurídico atingido por certas normas, enquanto a obligatio erga omnes seria pertinente à implicação jurídica decorrente da caracterização de uma norma como jus cogens. Destarte, a caracterização de uma norma jus cogens acarreta obrigações erga omnes quanto à observância da norma”. SALIBA, 2009, p.109.

${ }^{53}$ CANÇADO TRINDADE, 2005, p. 347. 
Considerando que todas as normas de jus cogens implicam em obrigações erga omnes, passa-se à análise do modo pelo qual tais obrigações são concretizadas no Direito Internacional contemporâneo.

Em uma primeira análise, as obrigações erga omnes vinculam a comunidade internacional como um todo e cada um dos Estados isoladamente. No entanto, se se considera o Direito Internacional por uma concepção positivista-voluntarista, cuja ênfase se encontra no consentimento do Estado como a base do exercício da jurisdição internacional, essa vinculação exclusiva dos Estados membros dos tratados internacionais fica ainda mais evidente.

No âmbito do Direito Internacional convencional, portanto, as obrigações erga omnes obrigam apenas os Estados Partes pelos tratados de direitos humanos que ratificaram (obrigações erga omnes partes).

Contudo, com desenvolvimento do Direito Internacional dos Direitos Humanos ${ }^{54}$, surge uma concepção universalista do Direito Internacional ${ }^{55}$. E, no âmbito desse Direito Internacional geral, o jus cogens vincula a todos os Estados que compõem a comunidade internacional organizada, independentemente de serem ou não partes nos tratados (obrigações erga omnes lato sensu).

Nesse diapasão, a antiga dimensão meramente interestatal do Direito Internacional é superada e a pessoa humana emerge como sujeito de direitos emanados diretamente do Direito Internacional.

\footnotetext{
${ }^{54}$ A consolidação do Direito Internacional dos Direitos Humanos é um fenômeno pós Segunda Guerra Mundial e seu desenvolvimento pode ser atribuído às atrocidades cometidas pelo Terceiro Reich. Durante o Regime Nazista, o positivismo jurídico permitiu o extermínio de onze milhões de pessoas, ao condicionar a titularidade de direitos apenas à raça pura ariana. Com o fim da guerra, tornou-se necessário a reconstrução dos direitos humanos como interesse internacional. Assim, a necessidade de uma ação internacional eficaz para a proteção dos direitos humanos impulsionou o processo de internacionalização dos direitos humanos, por meio de uma verdadeira humanização do direito internacional. Nesse sentido vide as obras: CANÇADO TRINDADE, Antônio Augusto. A Humanização do Direito Internacional. Belo Horizonte: Del Rey, 2006. PIOVESAN, Flávia. Direitos Humanos e o Direito Constitucional Internacional. São Paulo: Saraiva, 2008.

55 Cançado Trindade sustenta que no Direito Internacional contemporâneo verifica-se um verdadeiro renascimento da concepção universalista do direito internacional adotada pelos "fundadores" do Direito Internacional: Cícero, Tomás de Aquino, F. Vitoria, F. Suaréz, H. Grotius, C. Wolff, dentre outros. Nesse sentido, o autor afirma "parece-me de todo apropriado resgatar seus ensinamentos de um direito impessoal que é o mesmo para todos - não obstante as disparidades de poder, - e que situa a solidariedade acima da soberania, e que submete os diferendos ao juízo da recta ratio. O renascimento - que sustento firmemente - em nossos tempos desses ensinamentos clássicos, que ademais propugnam uma ampla concepção da personalidade jurídica internacional (incluindo os seres humanos, e a humanidade como um todo), pode certamente ajudar-nos a enfrentar mais adequadamente os problemas com que se defronta o Direito Internacional contemporâneo, movendo rumo a um novo jus gentium do século XXI, o Direito Internacional para a humanidade". CANÇADO TRINDADE, 2006, p. 16.
} 
Nesse contexto, não há como deixar de considerar a necessária vinculação dos particulares ao Direito Internacional. Já que os próprios indivíduos, em suas relações com o poder público ou com seus pares, também se encontram vinculados diretamente ao Direito Internacional e, indiscutivelmente, não raras vezes, acabam por viola-lo.

De acordo com o entendimento do autor Cançado Trindade, expresso em seu parecer favorável na Corte Interamericana de Direitos Humanos, quando da Opinião Consultiva sobre a Condição Jurídica e Direitos dos Migrantes Indocumentados ${ }^{56}$, as obrigações erga omnes necessariamente apresentam duas dimensões de eficácia, a saber: a dimensão horizontal e a dimensão vertical ${ }^{57}$.

Para Cançado Trindade, para além de vincular a comunidade internacional como um todo (dimensão horizontal), as normas de jus cogens e suas respectivas obrigações erga omnes vinculam não só os órgãos e agentes do poder público, mas também os particulares em suas relações inter $\operatorname{se}^{58}$ (dimensão vertical).

A guisa de exemplo, importa destacar a posição da Corte Interamericana de Direitos Humanos sobre o tema, que, nesse particular, foi expressa por Cançado Trindade, quando da análise da Opinião Consultiva sobre a condição jurídica e os direitos dos migrantes indocumentados ${ }^{59}$. Nessa oportunidade, a Corte entendeu que os trabalhadores migrantes, inclusive os indocumentados, são titulares de direitos fundamentais erga omnes. De modo que, o Estado e os próprios indivíduos são obrigados a proteger toda pessoa humana,

\footnotetext{
${ }_{57}^{56} \mathrm{CIDH}, 2003$, p. 31-36.

${ }^{57}$ Nesse sentido, Francisco de Vitória afirmava que o jus gentium se aplicava a todos os povos e seres humanos (mesmo sem o conhecimento de seus destinatários). Para Vitória, o jus gentium era direito para indivíduos e povos assim como Estados, toda fração da humanidade; o jus gentium conforma-se pelo consenso comum de todas as pessoas e nações. VITÓRIA, Franciso de. Os Índios e o Direito da Guerra. Ciro Mioranza (trad.). Rio Grande do Sul: Ijuí, 2006.

${ }^{58}$ CANÇADO TRINDADE, Antônio Augusto. El ejercicio de la función judicial internacional: memorias de la Corte Interamericana de Derechos Humanos. 2.ed. Belo Horizonte: Del Rey, 2013. p.133.

59 Trecho original: "Con ésto se puede asegurar prontamente un mínimo de protección convencional, por ejemplo, a los trabajadores migrantes indocumentados, en sus relaciones no sólo con el poder público sino también con otros individuos, en particular sus empleadores. Se puede, así, sostener que los trabajadores migrantes, inclusive los indocumentados, son titulares de derechos fundamentales erga omnes. En última instancia, el Estado tiene la obligación de tomar medidas positivas para impedir la explotación laboral inescrupulosa, y para poner fin a la misma. El Estado tiene el deber de asegurar la prevalencia del principio fundamental de la igualdad y no-discriminación, que, como lo establece con acierto la presente Opinión Consultiva de la Corte Interamericana, es un principio del jus cogens (párr. 101, y punto resolutivo n. 4). El haber aclararado este punto básico constituye una valiosa contribución de la presente Opinión Consultiva n. 18 de la Corte. El Estado está obligado por la normativa de la protección internacional de los derechos humanos, que protege a toda persona humana erga omnes, independientemente de su estatuto de ciudadanía, o de migración, o cualquier otra condición o circunstancia. Los derechos fundamentales de los trabajadores migrantes, inclusive los indocumentados, son oponibles al poder público e igualmente a los particulares (v.g., los empleadores), en las relaciones inter-individuales. El Estado no puede prevalecerse del hecho de no ser Parte en un determinado tratado de derechos humanos para evadirse de la obligación de respetar el principio fundamental de la igualdad y non-discriminación, por ser este un principio de derecho internacional general, y del jus cogens, que transciende así el dominio del derecho de los tratados". CIDH, 2003, p. 34-35.
} 
independentemente de seu estado de migração, cidadania ou qualquer outra circunstância. E conclui que, os direitos fundamentais dos trabalhadores migrantes indocumentados são oponíveis tanto ao poder público, quanto aos particulares em suas relações interindividuais (no caso, os empregadores).

Dessa forma, o não reconhecimento dos efeitos das normas de jus cogens vis-à-vis particulares, implicaria em dizer que as obrigações erga omnes de proteção se "reduziriam a pouco mais que letra morta"60.

Destarte, ao proteger direitos fundamentais à pessoa humana, o jus cogens, na concretização de obrigações erga omnes, dotada de um caráter objetivo, engloba todos os destinatários das normas jurídicas: sejam aqueles que integram os órgãos do poder público, sejam os particulares em suas relações interindividuais.

\subsection{A hierarquia normativa das normas de jus cogens no direito internacional}

Uma outra análise, igualmente importante, que advém do conceito de norma imperativa é exatamente a superioridade hierárquica dessas normas. Não se olvida que ao estabelecer que "a norma pertencente ao jus cogens é insuscetível de ser derrogada por outra norma que não seja uma norma pertencente ao mesmo jus cogens, a Convenção de Viena sobre o Direito dos Tratados apontou a existência de uma hierarquia normativa no Direito Internacional",61.

Vê-se que, para o Direito Internacional, as normas aceitas como inderrogáveis adquirem hierarquia superior frente a qualquer outra norma ou princípio que não tenha caráter de jus cogens. E, nesse caso, a norma imperativa ocupa o topo de uma ordem escalonada de normas.

Há também quem entenda que "o conceito de jus cogens é baseado em uma aceitação de valores fundamentais e superiores, por toda comunidade internacional, dentro do sistema e, em alguns aspectos, assemelham-se ao conceito de ordem pública internacional”. ${ }^{62}$

\footnotetext{
${ }^{60}$ CANÇADO TRINDADE, op.cit., p. 132.

${ }^{61}$ SALIBA, 2011, p. 455.

${ }^{62}$ FINKELSTEIN, Cláudio. Hierarquia das Normas no Direito Internacional: jus cogens e metaconstitucionalismo. São Paulo: Saraiva, 2013, p.199. Destaca-se que ORAKHELASHVILI, Alexander. State Immunity and Hierarchy of norms: why the House of Lords got it wrong. In: The Europen Journal of International Law. Vol. 18. no.5. EJIL 2008. p. 955-970, p.963, também segue essa linha. Cita-se: "peremptory
} 
Para Nasser, a Convenção de Viena sobre o Direito dos Tratados ao estabelecer que o jus cogens limita a autonomia dos Estados para tratarem entre si, acaba por conduzir ao reconhecimento da existência de uma ordem pública internacional ${ }^{63}$.

Nesse sentido, as normas de jus cogens são superiores porque podem ser vistas como de ordem pública, exatamente porque são inderrogáveis pela vontade de Estados contratante.

Por outro lado, Rubens Silveira acredita que, estando em um Estado Democrático de Direito, a discussão sobre a superioridade hierárquica de jus cogens é pouco adequada, embora na prática a imperatividade e a prioridade de tais normas geram o mesmo efeito ${ }^{64}$. Silveira é bastante sensível ao afirmar que, "no atual paradigma, apesar da validade formal e material do critério hierárquico, sobretudo no âmbito doméstico, a solução de antinomias está mais afeta à ponderação dos bens e valores envolvidos"

Assim, uma norma de jus cogens deve ter primazia aplicativa mais por representar os valores superiores da sociedade internacional, do que por estar em um patamar hierárquico estático superior ${ }^{66}$.

Fato é que, por um motivo ou por outro, é justamente devido à importância dos valores que protege, que a norma de jus cogens deve ser aplicada com primazia em face de todas as demais normas do direito interno e internacional. Existindo ou não existindo graus hierárquicos definidos, as normas imperativas são superiores às demais.

\section{NORMAS PROCESSUAIS E NORMAS SUBSTANTIVAS DE JUS COGENS}

\footnotetext{
norms ( jus cogens ) refer to the fundamental public order of the international community that trumps all inconsistent norms and instruments."

${ }^{63}$ NASSER, 2005, p.169. Ao analisar a hierarquia das normas de jus cogens por se tratar de questões de ordem pública, Salem Hikmat Nasser explica que "ordem pública é um conceito mais ou menos fluido que remete a uma ideia de ordem política, social e jurídica de dada comunidade, em geral de um Estado. Assim, a ordem pública, expressa também em normas jurídicas, mas não restrita a elas, estabelece os limites dentro dos quais os sujeitos de direito podem exercer a sua liberdade de contratar, da autonomia da vontade. Ela também deverá ser observada e protegida quando do reconhecimento de atos de autoridades estrangeiras, sentenças estrangeiras, laudos arbitrais e outros. Finalmente, quando um juiz for chamado a aplicar uma lei estrangeira, essa aplicação poderá ser afastada se o seu resultado for visto como ofensivo à ordem pública. Mais uma vez, transferir um conceito típico dos direitos nacionais para uma sociedade tão diferente, e tão hererogênea, como a internacional, e tentar identificar nesta uma cor de valores comuns não é tarefa fácil. Mas, por outro lado, já que se trata de conceito fluido e incerto, tampouco parece necessariamente possível”.

${ }^{64}$ SILVEIRA, Rubens Curado. A Imunidade de Jurisdição dos Organismos Internacionais e os Direitos Humanos. São Paulo: Editora LTR, 2007, p.55.

${ }^{65}$ Ibid., p. 55.

${ }^{66}$ Ibid., p. 55.
} 
Depois de analisar pormenorizadamente as principais características e efeitos das normas inderrogáveis, impõe-se a necessidade de voltar para o cerne da questão: a distinção entre normas processuais e normas substantivas.

Normas substantivas, incluindo as normas de jus cogens, determinam direta ou indiretamente se uma conduta ou situação específica é legal ou ilegal ${ }^{67}$. Essas normas prescrevem direitos, obrigações e normas de conduta, determinam status de legalidade, fornece definições legais e estabelecem responsabilidade internacional do Estado ${ }^{68}$ (ou até do indivíduo).

As normas processuais, por outro lado, poderiam ser definidas negativamente como todas as normas que não incidem sobre a questão de saber se uma conduta particular é legal ou ilegal ${ }^{69}$. Mas essa definição não é a mais adequada. É muito ampla e imprecisa ${ }^{70}$. Sugerese, em termos positivos, que "as normas processuais são normas judiciais ou administrativas de interpretação, implementação e execução das regras substantivas"71. Essas normas estabelecem o que deve ser feito para tornar eficaz o que determinam as normas substantivas. A função delas é literalmente "colocar em prática" as normas substantivas.

Assim, a título de exemplo, são normas processuais as regras relativas à competência dos tribunais, incluindo regras sobre a imunidade de jurisdição, regras sobre a admissibilidade de uma ação ou petição, as regras de procedimento, bem como as regras relativas à implementação da responsabilidade internacional dos Estados e organizações internacionais. Como tal, elas estão intimamente ligadas às questões de recursos e reparações ${ }^{72}$.

A distinção causa muita polêmica entre os estudiosos do direito internacional. Antônio Cassesse entende que essa dicotomia substantivo-processual é absolutamente sólida e deve ser considerada ${ }^{73}$.

Alguns autores, no entanto, discutem a relevância dessa distinção. Nesse sentido, Alexander Orakhelashvili pontua que:

\footnotetext{
${ }^{67}$ CIJ, 2012, parágrafo 58.

${ }^{68}$ TALMON, 2012, p.4.

${ }^{69}$ Cf. CIJ, 2012, parágrafo 93.

${ }^{70}$ TALMON, op. cit., p. 5.

${ }^{71}$ Ibid., p. 5.

72 Ibid., p. 5. O autor complementa dizendo que não se pode dizer que „normas processuais" é o mesmo que „,normas secundárias" (como pretendeu a Alemanha em suas alegações - vide notas 18 e 19). Segundo ele, as regras secundárias dizem as condições gerais no direito internacional para que um Estado ou uma Organização Internacional possa ser considerado responsável por atos ou omissões ilegais, e suas respectivas consequências jurídicas. Nesse sentido, a violação das normas processuais pode, dependendo da circunstância, dar origem a "obrigações secundárias".

${ }^{73}$ CASSESSE, Antônio. When May Senior State Officials Be Tried for Internationa Crimes? Some
} Comments on the Congo v. Belgium case. EJIL 2002, vol.13, no.4. p.853-875, p. 867. 
"O direito internacional não conhece a distinção clara entre normas substantivas e processuais. Todas as normas internacionais derivam do acordo entre Estados ou da aceitação por parte da comunidade internacional como um todo, e não existem critérios estabelecidos, nem uma agência reconhecida para dividi-los em tais categorias ${ }^{74}$.

O juiz da CIJ, Antônio Augusto Cançado Trindade, com visão centrada na humanização do direito internacional, também acredita na irrelevância da distinção:

\begin{abstract}
“(...) conceituações inadequadas e pouco convincentes, tão difundidas na profissão do advogado, como, entre outras, as contraposições de regras „primárias" e „secundárias", regras „processuais" e „substantivas ${ }^{\text {e" }}$, obrigações „,de conduta" e „de resultado" [são] palavras, palavras, palavras... Onde estão os valores?"75
\end{abstract}

E continua: "para mim, a separação entre direito processual e substantivo não é ontologicamente, nem deontologicamente viável. (...) Procedimento legal não é um fim em si mesmo, é um meio para a realização da justiça. E a aplicação do direito substantivo é finalista, se propõe a fazer justiça" ${ }^{\text {, }}$.

Nessa linha de entendimento, mesmo acreditando que a distinção, por si só, não se justifica, vê-se a necessidade de entender a relação entre tais normas. Ademais, ambas fazem parte do direito e têm sua respectiva importância.

Na literatura brasileira, Cândido Rangel Dinamarco, defende a ideia de que o direito processual, as normas processuais e especificamente o processo funcionam como instrumento do direito substantivo. Como instrumento, ele "é meio; e todo meio só é tal e se legitima, em função dos fins a que se destina" ${ }^{\prime 7}$. Nessa linha, o autor ensina que o raciocínio teleológico há de incluir, necessariamente, a fixação dos escopos, das finalidades, dos objetivos do processo. Em outras palavras, o processo só tem sentido se guiado pelos propósitos norteadores da sua instituição.

Para Dinamarco, uma norma processual deve ter, concomitantemente, o escopo social, o político e o jurídico. Vale dizer, o processo é um meio pelo qual se atinge, ao mesmo tempo, uma finalidade social, uma política e uma jurídica. E, todas elas, evidentemente, devem se relacionar, e nunca se anular.

\footnotetext{
${ }^{74}$ ORAKHELASHVILI, Alexander. State Immunity and Hierarchy of Normas: why the House of Lords got it wrong. In: The European Journal of International Law. Vol. 18. no. 5. EJIL 2008, p. 968.

75 CIJ. Dissenting Opinion of judge Cançado Trindade Jurisdictional Immunities of the State (Germany v. Italy: Greece intervening). 2012. Paragrafo 294. Disponível em: < http://www.icjcij.org/docket/files/143/16891.pdf>. Acessado em: 20 de junho de 2014.

${ }^{76}$ Ibid., parágrafo 295.

77 DINAMARCO, Cândido Rangel. A Instrumentalidade do Processo. 13.ed. São Paulo: Malheiros Editores, 2008, p. 177.
} 
Em resumo, os escopos sociais se ligam com a ideia de justiça, de paz social, de permitir aos cidadãos e à sociedade a fruição dos direitos substantivos. Na análise dos escopos sociais do processo, não se pode perder de vista o fundamento último do direito: a proteção do ser humano ${ }^{78}$.

Nesse ponto, Scarpinella Bueno faz um comentário interessante: "é como se fosse dito que o próprio Estado (aqui a parcela jurisdicional dele, o Estado-Juiz) precisa, ele próprio, do „processo" e, mais amplamente, das normas processuais para realizar os seus próprios valores, os seus próprios objetivos, as suas próprias finalidades e necessidades"79.

Os escopos políticos, por sua vez, traz à tona a autoridade e o poder do órgão julgador perante a sociedade. Porquanto, os escopos jurídicos representam a compreensão dos institutos processuais e seu desenvolvimento com o intuito de efetivar os objetivos mais amplos, exteriores ao processo, que são o social e o político.

Sob o enfoque da instrumentalidade, as normas substantivas doam sentido e guiam as normas processuais. As normas processuais, por seu turno, cuidam de realizar as normas substantivas.

Se se inclui a característica de jus cogens nas normas substantivas, a relação de dependência fica ainda mais evidente. Pois, se as normas de jus cogens dispõem sobre os valores superiores da comunidade internacional, as normas processuais internacionais devem servir de meio para a realização dos propósitos daquelas.

Todas as normas do direito devem respeitar as normas imperativas e contribuir para a efetivação delas. Do contrário, ter-se-ia um ordenamento jurídico insustentável e contraditório.

Dessa forma, no caso em espeque, ainda que não se considere a existência de conflito entre a norma processual de imunidade de Estado e a norma substantiva de jus cogens, a norma processual não pode ser invocada, porque sua aplicabilidade resulta em violação à norma imperativa. E, por conseguinte, em impunidade e injustiça manifesta.

A decisão da CIJ no caso Alemanha v. Itália não poderia ser mais incompatível com a essência do direito internacional contemporâneo ${ }^{80}$. Parece que algo precisa ser feito para

\footnotetext{
${ }^{78}$ CANÇADO TRINDADE, 2006, p. 12.

${ }^{79}$ BUENO, Cassio Scarpinella. Curso Sistematizado de Direito Processual Civil. 4.ed. São Paulo: Editora Saraiva. 2010, p.86.

${ }^{80}$ Cita-se: "No novo jus gentium do século XXI o ser humano emerge como sujeito de direitos emanados diretamente do Direito Internacional, dotado de capacidade processual para vindica-los. Permitir-me-ei caracterizar esta evolução mais ampla como a da reconstrução do jus gentium, consoante a recta ratio, como um novo e verdadeiro direito universal da humanidade. Mediante sua humanização e universalização, o direito internacional contemporâneo passa a ocupar-se mais diretamente da identificação e realização de valores e metas
} 
trazer o direito processual internacional em linha com a humanização do direito. "O procedimento judicial internacional, embora tenha desenvolvido muito notavelmente, especialmente desde 1945, ainda é lançado em um molde do século XIX, e o bilateralismo estrito do contencioso internacional é um dos seus traços distintivos" ${ }^{\prime 81}$.

Stefan Talmon, ao afirmar que a crítica ou a negação pura e simples da distinção substantiva-processual em direito internacional foi motivada mais pelo resultado esperado de manter os violadores de jus cogens responsáveis do que por qualquer argumento substancial contra a distinção em si $^{82}$, não considerou a importância de se analisar o direito como uma ciência social aplicada. A discussão da distinção por si só não passa de um "formalismo excessivo" ${ }^{" 83}$. As consequências injustas e incompatíveis com o direito internacional é o que justifica o estudo da problemática.

Nesse sentido, Alexander Orakhelashvili, importante defensor da supremacia do jus cogens, com exatidão, conclui que "a chamada distinção entre normas „substantivas" e „processuais" que impede a aplicação das relevantes normas de jus cogens deve ser rejeitada por levar necessariamente à impunidade" ${ }^{\prime 84}$.

E, embora a CIJ tenha decidido ao contrário, a opinião divergente do juiz Cançado Trindade não permite que a polêmica chegue ao fim. O voto dissidente tem sua relevância. Não é um precedente, mas sem dúvidas serve de parâmetro para os próximos casos que envolverem jus cogens. Afinal, é como o próprio Cançado Trindade diz: "sem a primazia do jus cogens, o direito internacional teria um futuro sombrio. Eu não podia aceitar isso, que toda a esperança de um futuro melhor, então, desaparecesse" ${ }^{, 85}$.

\section{CONCLUSÃO}

comuns superiores, que dizem respeito à humanidade como um todo. (...) Tal como me permiti assinalar em meu Voto Concordante no Parecer n. 16, da Corte Interamericana de Direitos Humanos, sobre o Direito à Informação sobre a Assistência Consular no Âmbito das Garantias do Devido Processo Legal (1999): „toda jurisprudência internacional em matéria de direitos humanos tem desenvolvido, de forma convergente, ao longo das últimas décadas, uma interpretação dinâmica ou evolutiva dos tratados de proteção dos direitos do ser humano. (...) As próprias emergências e consolidação do corpus juris do Direito Internacional dos Direitos Humanos se devem à reação da consciência jurídica universal ante os recorrentes abusos cometidos contra os seres humanos, frequentemente convalidados pela lei positiva: com isto, o Direito veio ao encontro do ser humano, destinatário último de suas normas de proteção (parágrafos 3-4) ee". CANÇADO TRINDADE, 2006, p. 18-19.

${ }^{81}$ S. ROSENNE apud CANDÇADO TRINDADE, 2005, p.349.

82 TALMON, 2012, p.29.

${ }^{83}$ Vide notas 12 e 14.

${ }^{84}$ ORAKHELASHVILI, Alexander. State Immunity and International Public Order Revisited. GYIL 2006, V.49. p. $327-365$, p. 361 .

${ }^{85}$ CANÇADO TRINDADE, 2012, paragrafo 288. 
De acordo com o Direito Internacional contemporâneo, não é possível que a norma processual de imunidade de Estado impeça a aplicação da norma substantiva de jus cogens proibitiva da tortura e do trabalho escravo.

Os valores protegidos pela norma imperativa doam sentido e servem de guia para todo o ordenamento jurídico internacional.

As normas de jus cogens têm primazia aplicativa por representar os valores superiores da sociedade internacional e os contornos do direito. Porquanto, as normas processuais, incluindo a norma de imunidade de Estados são verdadeiros instrumentos que garantem a consecução dos comandos substantivos do direito internacional.

Ao desconsiderar uma norma de jus cogens, a decisão da CIJ no caso Alemanha v. Itália resultou em impunidade e injustiça manifesta.

As normas processuais do direito internacional não podem continuar sendo abordadas isoladamente. O direito é uma ciência social aplicada, e como tal, todas as normas que o compõem, sejam elas processuais ou substantivas, devem ser guiadas para uma mesma direção.

A pessoa humana é a finalidade última do direito internacional, devendo esse atender as necessidades daquela, incluindo a realização da justiça, ou, em outras palavras, o efetivo acesso material à justiça.

Normas processuais e substantivas devem ser abordadas em uma visão abrangente do Direito Internacional contemporâneo e do seu papel na comunidade internacional. Pois, só assim, o direito terá condições de resolver, ou pelo menos minimizar, as situações de graves violações às normas mais fundamentais da pessoa humana. 


\section{REFERÊNCIAS BIBLIOGRÁFICAS}

A MENINA que roubava livros. Direção: Brian Percival. Interpretes: Geoffrey Rush; Emily Watson, Sophie Nélisse; e outros. DVD. EUA / Alemanha, 2014.

A VIDA é bela. Direção: Roberto Benigni. Produção: Gianluigi Braschi; Elda Ferri. Interpretes: Roberto Benigni; Nicoletta Braschi; e outros. DVD. Itália, 1997. BIANCHI, Andrea. Human Rights and the Magic of Jus Cogens. In: The European Journal of International Law. vol.19. n.3. 2008.

BORNKAMM, Paul Christoph. State Immunity Against Claims Arising from War Crimes: The Judgment of the International Court of Justice in Jurisdictional Immunities of the State. Disponível em: <http://www.germanlawjournal.com/pdfs/Vol13No6/PDF_Vol_13_No_06_773-782_Bornkamm\%20FINAL.pdf $>$. Acesso em: 26 de novembro de 2013.

BUENO, Cassio Scarpinella. Curso Sistematizado de Direito Processual Civil. 4.ed. São Paulo: Editora Saraiva, 2010.

CANÇADO TRINDADE, Antônio Augusto. A Humanização do Direito Internacional. Belo Horizonte: Del Rey, 2006.

A visão Humanista do Direito Internacional. Belo Horizonte: Del Rey, 2013.

El ejercicio de la función judicial internacional: memorias de la Corte Interamericana de Derechos Humanos. 2.ed. Belo Horizonte: Del Rey, 2013.

International Law for Hamankind: Towards a New Jus Gentium - General Course on Public International Law - Part I, in Hague Academy of International Law. Offprint from the Collected Courses. vol. 316, Martinus Nijhoff Publishers, 2005.

.Jus Cogens: The determination and the gradual expansion of its material contente in contemporary international case-law. Disponível em: < http://www.oas.org/dil/esp/3\%20-\%20cancado.LR.CV.3-30.pdf >. Acessado em: 04 de março de 2014.

Tratado de Direito Internacional dos Direitos Humanos. vol.I. 2.ed. Porto Alegre: Sergio Antonio Fabris Editor, 2003.

CAPPELLETO, Francesca. Memory and World War II: na ethnographic approach. New York: BERG OXFORD, 2005.

CASSESSE, Antônio. When May Senior State Officials Be Tried for Internationa Crimes? Some Comments on the Congo v. Belgium case. EJIL 2002, vol.13, no.4. p.853875.

CIDH. Opinión Consultiva OC-18/03. Solicitada por los Estados Unidos Mexicanos. Condición Jurídica y Derechos de los Migrantes Indocumentados. Disponível em: $<$ http://www.cdh.uchile.cl/media/publicaciones/pdf/15/229.pdf $>$. Acessado em: 03 de abril de 
2014.

CIJ. Application for permission to intervene by the government of the Hellenic Republic. 13 de janeiro de 2011. Disponível em: < http://www.icj-cij.org/docket/files/143/16304.pdf>. Acessado em: 22 de novembro de 2013.

CIJ. Application Instituting Proceedings Jurisdictional Immunities of the State (Germany v. Italy) de 23 december 2008. Disponível em: <http://www.icjcij.org/docket/files/143/14923.pdf>. Acessado em: 20 de janeiro de 2014.

CIJ. Counter-Memorial of Itália 22 de dezembro de 2009. Disponível em: < http://www.icjcij.org/docket/files/143/16648.pdf>. Acessado em 26 de novembro de 2013.

CIJ. Dissenting Opinion of judge Cançado Trindade Jurisdictional Immunities of the State (Germany v. Italy: Greece intervening). 2012. Paragrafo 294. Disponível em: < http://www.icj-cij.org/docket/files/143/16891.pdf>. Acessado em: 20 de junho de 2014.

CIJ. Judgment of 5 February 1970 Barcelona Traction, Light and Power Company, Limited (Belgium v. Spain). ICJ Reports 1970, p. 32, parágrafos 33 e 34. Disponível em: < http://www.icj-cij.org/docket/index.php?p1=3\&p2=3\&k=4e\&case=41\&code=bt\&p3=6>. Acessado em: 02 de junho de 2014.

CIJ. Judgment Jurisdictional Immunities of the State (Germany v. Italy; Greece intervening). ICJ Reports, 3 February 2012 . Disponível em: <http://www.icj-

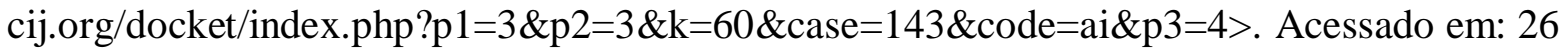
de novembro de 2013.

CIJ. Memorial of the Federal Republic of Germany Jurisdictional Immunities of the State (Germany v. Italy: Greece intervening). 12 de junho de 2009. Parágrafo 87. Disponível em: < http://www.icj-cij.org/docket/files/143/16644.pdf>. Acessado em: 20 de janeiro de 2014.

CIJ. Public sitting held on Monday 12 September 2011, at 10 a.m., at the Peace Palace, President Owada presiding, in the case concerning Jurisdictional Immunities of the State (Germany $v$. Italy: Greece intervening). CR 2011/17. p. 49-50, parágrafo 3.

Disponível em: <http://www.icj-

cij.org/docket/index.php?p1=3\&p2=3\&k=60\&case $=143 \&$ code $=$ ai $\& p 3=2>$. Acessado em: 20 de janeiro de 2014.

CIJ. Public sitting held on Tuesday 13 September 2011, at 10 a.m., at the Peace Palace, President Owada presiding, in the case concerning Jurisdictional Immunities of the State (Germany v. Italy: Greece intervening). CR 2011/18. p. 47-48, parágrafo 25. Disponível em: <http://www.icjcij.org/docket/index.php?p1=3\&p2=3\&k=60\&case $=143 \&$ code=ai $\& \mathrm{p} 3=2>$. Acessado em: 20 de janeiro de 2014.

CIJ. Public sitting held on Wednesday 14 September 2011, at 10 a.m., at the Peace Palace, President Owada presiding, in the case concerning Jurisdictional Immunities of the State (Germany v. Italy: Greece intervening). CR 2011/19. p. 36, parágrafo 98. Disponível em: < http://www.icj- 
cij.org/docket/index.php?p1 $=3 \& \mathrm{p} 2=3 \& \mathrm{k}=60 \&$ case $=143 \&$ code $=$ ai $\& \mathrm{p} 3=2>$. Acessado em: 20 de janeiro de 2014 .

\section{CIJ. Reports of Judgments Case Concerning The Arrent Warrant of 11 April 2000}

(Democratic Republic Of The Congo V. Belgium). Judgment of 14 february 2002.

Parágrafo 60. Disponível em: < http://www.icj-cij.org/docket/files/121/8126.pdf>. Acessado em 16 de junho de 2014.

CIJ. Summary of the Judgment of 3 February 2012. Jurisdictional Immunities of the State (Germany v. Italy; Greece intervening). 2012. p. 4. Disponível em: < http://www.icjcij.org/docket/files/143/16899.pdf>. Acessado em: 20 de dezembro de 2013.

D"AMATO, Anthony. It"s a Bird, it"s a plane, it"s jus cogens. In: Connecticut Journal of International Law, v.6, n.1, p. 1-6, 1990.

DINAMARCO, Cândido Rangel. A Instrumentalidade do Processo. 13.ed. São Paulo: Malheiros Editores, 2008.

FINKELSTEIN, Cláudio. Hierarquia das Normas no Direito Internacional: jus cogens e metaconstitucionalismo. São Paulo: Saraiva, 2013.

MAZOWER, Mark. O Império de Hitler: a Europa sob o domínio Nazista. Tradução Cláudio Carina; Lúcia Boldrini. 1.ed. São Paulo: Companhia das Letras, 2013.

MC GREGOR , Lorna. Torture and State Immunity: Deflecting Impunity, Distorting Sovereignty. In: EJIL 18, páginas 903-911, 2007.

NASSER, Salem Hikmat. Jus Cogens: ainda esse desconhecido. In: Revista Direito GV 2. v.1. n.2. 2005.

O JULGAMENTO de Nuremberg. Direção: Yves Simoneau. Interpretes: Alec Baldwin; Brian Cox; e outros. Estúdio: Warner Home Vídeo. Duração: 180 minutos. DVD. Canadá / EUA, 2000 .

ONU. Yearbook of the International Law Commission (1976). Vol. II. parte II. 1976.

Disponível em: < http://legal.un.org/ilc/publications/yearbooks/1976.htm>. Acessado em: 20 de maio de 2014.

ORAKHELASHVILI, Alexander. State Immunity and Hierarchy of norms: why the House of Lords got it wrong. In: The Europen Journal of International Law. Vol. 18. no.5. EJIL 2008.

ORAKHELASHVILI, Alexander. State Immunity and International Public Order Revisited. GYIL 2006, v.49. p. 327-365.

PAULUS, Andreas L. Jus Cogens in a Time of Hegemony and Fragmentation: an attempt at a re-appraisal. In: Nordic Journal of International Law. 74. 2005.

PAVONI, Riccardo. Human Rights and the Immunities of Foreign States and International Organizations. In: DE WET, Erika; VIDMAR, Jure (edited). Hierarchy in International Law: The Place of Human Rights. Oxford, 2012. 
PIOVESAN, Flávia. A Proteção dos Direitos Humanos no Sistema Constitucional Brasileiro. In: Revista de Direito Constitucional e Internacional. vol.45. out/2003.

. A Proteção Internacional dos Direitos Humanos e o Direito Brasileiro. In: Doutrinas Essenciais de Direitos Humanos. vol.6. Ago/2011. 2008.

Direitos Humanos e o Direito Constitucional Internacional. São Paulo: Saraiva,

SALIBA, Aziz Tuffi. A Imunidade absoluta de jurisdição de Estados: "sólida regra costumeira" ou mito? In: ALMEIDA, Gregório Assagra de; GOMES JUNIOR, Luiz Manoel; SALIBA, Aziz Tuffi (orgs). Direitos Fundamentais e sua proteção nos planos interno e internacional. Belo Horizonte: Arraes em parceria com a Universidade de Itaúna, v. I e II. 2010. 2009.

Conselho de Segurança da ONU: sanções e limites jurídicos. Curitiba: Juruá,

Direito dos Tratados: comentários à Convenção de Viena sobre o direito dos tratados (1969). Aziz Tuffi Saliba, autor e organizador; Ana Cristina Zadra Valadares e André de Carvalho Ramos. Belo Horizonte: Arraes Editores, 2011.

SILVEIRA, Rubens Curado. A Imunidade de Jurisdição dos Organismos Internacionais e os Direitos Humanos. São Paulo: Editora LTR, 2007.

TALMON, Stefan. Jus Cogens after Germany v. Italy: Substantive and Procedural Rules Distinguished. In: Bonn Research Papers on Public International Law. Paper n. 4/2012, 16 de junho de 2012.

TUNKIN, Grigory I. Jus Cogens in Contemporary International Law. 3U. Tol. L. Rev. 107, 1971. Disponível em: <http://heinonline.org>. Acessado em: 25 de fevereiro de 2014.

VITÓRIA, Franciso de. Os Índios e o Direito da Guerra. Ciro Mioranza (trad.). Rio Grande do Sul: Ijuí, 2006.

ZWEIG, Stefan. O Mundo que eu vi (minhas memórias). Tradução Odilon Gallotti. Rio de Janeiro: Guanabara, 1942. 